\title{
Xylia xylocarpa (Roxb.) Taub. Leaves Ameliorates Inflammation and Pain in Experimental Mice and Computer-Aided Model
}

\author{
Kamrul Hasan CHOWDHURY, Riad CHOWDHUR, \\ Mehedi HASAN, Mohammad Jamir UDDIN, Zahid HASAN, \\ Samima NASRIN and A. S. M. Ali REZA* \\ Department of Pharmacy, International Islamic University Chittagong, Chittagong 4318, Bangladesh
}

('Corresponding author’s e-mail: alirezaru@gmail.com)

Received: 21 March 2021, Revised: 22 April 2021, Accepted: 29 April 2021

\begin{abstract}
Xylia xylocarpa (Roxb.) Taub. is traditionally used to treat several diseases, including leprosy, wound healing, gonorrhea, rheumatism, anemia, diarrhea and ulcer. This study evaluated the antiinflammatory and anti-nociceptive activities of methanolic extract of Xylia xylocarpa leaves (MEXX) via in vitro, in vivo as well as in silico models. In vitro anti-inflammatory activity was determined by human red blood cell membrane stabilization study and protein denaturation while in vivo anti-nociceptive activity was examined by the acetic acid-induced writhing test (AAWT) and formalin-induced paw licking test (FIPLT). Additionally, trans-5-hydroxypipecolic acid was an identified compound of MEXX which was subjected to molecular docking analysis followed by ADME/T and toxicity analysis. Qualitative phytochemical screening revealed that MEXX was enriched with carbohydrates, flavonoids, alkaloids, proteins, tannins and showed significant total phenolic (1222.66 $\pm 0.66 \mathrm{mg}$ GAE/g dried extract) and flavonoids contents $(325.33 \pm 1.76 \mathrm{mg} \mathrm{QE} / \mathrm{g}$ dried extract) in quantitative phytochemical screening. Inflammatory studies unveiled that; MEXX significantly $(p<0.05)$ inhibited the hemolysis of membrane and protein at different concentrations $(31.25-1000 \mu \mathrm{g} / \mathrm{mL})$. The extract also displayed statistically significant analgesic responses in the acetic acid and formalin-induced test at several doses (200 and $400 \mathrm{mg} / \mathrm{kg}$ b.w). In AAWT, the extract exhibited 13.67 and $51.37 \%$ inhibition of writhing at the doses 200 and $400 \mathrm{mg} / \mathrm{kg}$ body weight respectively. In formalin-induced paw licking test, the early phase pain inhibition was $54.64 \%$ at the concentration of $400 \mathrm{mg} / \mathrm{kg}$ while during the latter phase at $400 \mathrm{mg} / \mathrm{kg}$, the inhibition of pain was $43.82 \%$. According to molecular docking analysis, trans-5-hydroxypipecolic acid demonstrated a promising docking score against PDE4, COX-1, and COX-2 along with satisfied pharmacokinetic and toxicological properties. Finally, from the results it could be concluded that MEXX has potential anti-inflammatory and an-nociceptive effects that should require further investigation.
\end{abstract}

Keywords: Xylia xylocarpa, Anti-inflammatory, Anti-nociceptive, Trans-5-hydroxypipecolic, Molecular docking

\section{Introduction}

Inflammation is described as a normal protective and complicated biological feedback to vascular tissue damage due to injury or irritation of cells by pathogens, physical trauma, or noxious chemicals which is identified by warmth, redness, swelling and pain [1-3]. All pain is characterized by inflammation, which is mediated by the release of inflammatory mediators such as cyclooxygenase (COX), prostaglandins (PGs), cytokines, etc. [4]. Thus, pain is conceivably described as the irregular sensory counter-responses including the emotional responses generated by the nociceptors which result in inflammation, potential tissue injury, muscle cramp, nerve injury, openness to noxious provocation such 
as chemicals, heat, cold and mechanical stimulant [5]. In addition, prolonged inflammation and pain lead to hay fever, atherosclerosis, rheumatoid arthritis, ischemic heart diseases [5]. It has been statistically depicted that each year approximately $20 \%$ of adults ( 1 in 5) suffer from pain while another $10 \%$ of adults (1 in 10) are being diagnosed newly with chronic pain [6]. Accordingly, the recent therapeutic management for pain and inflammation comprised of NSAIDs (non-steroidal anti-inflammatory drugs), opioids, acetaminophen as well as anticonvulsants [4]. However, these agents are insufficient to prevent swelling and pain from inflammation clinically and have severe adverse effects such as nausea, vomiting, dependence, addiction, respiratory depression, cardiovascular and gastro-intestinal toxicity [6]. Consequently, there are still major requirements of potential anti-nociceptive and anti-inflammatory drugs possessing fewer side effects. Hence, medicinal plants are being used for the treatment of various diseases due to their wide-ranged pharmacological activities along with safety [7]. Xylia xylocarpa (Roxb.) Taub. is one of the most deciduous trees in South Asia which belongs to the family of Fabaceae and locally known as "Lohakath" in Bengali and "Ironwood" in English [8]. The people use Xylia xylocarpa barks for healing diarrhea and leaves for treating wounds in elephants [8]. Moreover, the oil from the seeds of Xylia xylocarpa use for the treatment of stiffness and infection [8]. Flowers and heartwoods of the plant are useful in rheumatism, gonorrhea, leprosy, anemia as well as ulcer [8]. Previous research suggests that wood of Xylia xylocarpa possesses anti-cholinesterase and memory-improving effects [9]. Also, the sawdust of this plant was found to act as a potent antimicrobial and antioxidant agent [10]. Furthermore, Xylia xylocarpa leaves contained trans-5- hydroxypipecolic acid compounds identified by 13 C NMR spectroscopy [11]. Despite various activities of Xylia xylocarpa, there is no scientific documentation to understand the mechanism of anti-inflammatory and anti-nociceptive activities. Therefore, the objective of our present study has been designed to evaluate the anti-inflammatory and anti-nociceptive effects of methanolic extract of Xylia xylocarpa leaves through in vitro and in vivo investigation. In addition, identified compound trans-5-hydroxypipecolic acid of the plant is subjected to investigate binding affinities against inflammatory mediators through in silico approach using molecular docking.

\section{Materials and methods}

\section{Plant collection and extraction}

Leaves of Xylia xylocarpa (Roxb.) Taub. were collected from Bangladesh Forest Research Institute, Chittagong, Bangladesh in August 2019. The plant was identified by Bangladesh Forest Research Institute, Chittagong, Bangladesh. Leaves were dried for 15 days and subsequently grinded into a coarse powder using a grinding machine. The powders $(500 \mathrm{~g})$ were then soaked into an adequate amount of methanol (1L) for 10 days at room temperature with occasional agitation and stirring. Afterward, the mixture was filtrated through a cotton plug followed by Whitman filter paper and then the solvent evaporation process was initiated using a water bath at $50{ }^{\circ} \mathrm{C}$ temperature. Finally, semisolid methanol extract of Xylia xylocarpa (Roxb.) Taub. (MEXX) was obtained and protected into a refrigerator for further use.

\section{Drugs and reagents}

Acetic acid, formalin, and methanol used in this study were purchased from local supplier Taj Scientific Ltd, Chittagong, Bangladesh. Hydrocortisone and diclofenac sodium was obtained from Square Pharmaceuticals Ltd, Dhaka, Bangladesh. All other reagents used in this experiment were of analytical grade unless otherwise specified.

\section{Qualitative and quantitative phytochemical screening}

Qualitative phytochemical screening of MEXX was determined by following standard procedures described previously [2]. On the other hand, quantitative screening of total phenolic and flavonoid contents of the extract was determined by the Folin-Ciocalteu method and Aluminium chloride $\left(\mathrm{AlCl}_{3}\right)$ methods respectively [3]. 


\section{In vitro anti-inflammatory potential}

Membrane stabilization activity

Membrane stabilization is a widely used method to evaluate in vitro anti-inflammatory activity of plant extract [6]. At first, fresh blood from healthy human volunteers was collected and mixed with the same volume of sterilized Alsever solution ( $2 \%$ dextrose, $0.8 \%$ sodium citrate, $0.05 \%$ citric acid and $0.42 \%$ sodium chloride in water) and then centrifuged simultaneously at $3000 \mathrm{rpm}$ for $10 \mathrm{~min}$. The test samples contained MEXX solution and hydrocortisone (standard) at different concentrations (31.25 $1000 \mu \mathrm{g} / \mathrm{mL})$ including $0.50 \mathrm{~mL}$ of human red blood cell suspension, $2 \mathrm{~mL}$ of hyposaline $(0.36 \%)$ and 1 $\mathrm{mL}$ of sodium phosphate buffer $(0.15 \mathrm{M}, \mathrm{pH} 7.4)$. Afterward, the solutions were subjected to incubation at $37{ }^{\circ} \mathrm{C}$ for $30 \mathrm{~min}$ and centrifuged again for $20 \mathrm{~min}$ at $3000 \mathrm{rpm}$. The absorbance of the hemoglobin content in the supernatant solution was measured using a spectrophotometer at $560 \mathrm{~nm}$. The percent inhibition of hemolysis or membrane stabilization was calculated as follows:

$\%$ Inhibition of hemolysis $=100 \times\left[\mathrm{A}_{1}-\mathrm{A}_{2} / \mathrm{A}_{1}\right]$

where $A_{1}=$ absorbance of hypotonic buffered solution alone

$\mathrm{A}_{2}=$ absorbance of test / standard sample in hypotonic solution.

\section{Inhibition potential of protein denaturation}

The anti-inflammatory activity of MEXX was further evaluated through the inhibitory potential of the bovine serum albumin (BSA) denaturation method according to a previous technique with slight modification [12]. The test solution consisted of $0.05 \mathrm{~mL}$ of test samples and $0.45 \mathrm{~mL}$ of BSA $(5 \% \mathrm{w} / \mathrm{v}$ aqueous solution) whereas the control solution was comprised of distilled water $(0.05 \mathrm{~mL}) \mathrm{with} 5 \% \mathrm{w} / \mathrm{v}$ aqueous solution of BSA $(0.45 \mathrm{~mL})$. Different concentrations $(31.25-1000 \mu \mathrm{g} / \mathrm{mL})$ of MEXX and diclofenac sodium were prepared and the $\mathrm{pH}$ (6.3) of all solutions was adjusted using $1 \mathrm{~N}$ hydrochloric acid. The mixtures were then incubated for $20 \mathrm{~min}$ at $37{ }^{\circ} \mathrm{C}$ and then heated at $57{ }^{\circ} \mathrm{C}$ for $3 \mathrm{~min}$. After cooling the sample solutions, phosphate buffer $(2.5 \mathrm{~mL})$ was added, and the absorbance was taken at 416 $\mathrm{nm}$. The percentage of protein denaturation inhibition was calculated by using the following formula:

$\%$ Inhibition of protein denaturation $=100 \times\left[\mathrm{A}_{\mathrm{c}}-\mathrm{A}_{\mathrm{s}} / \mathrm{A}_{\mathrm{c}}\right]$

where $\mathrm{A}_{\mathrm{c}}=$ absorbance of the control and $\mathrm{A}_{\mathrm{s}}=$ absorbance of the sample.

\section{Experimental animals}

Swiss-Albino mice (weight: 25 - 36 g) of both sexes (aging about 4 - 6 weeks) were collected from the animal research division of the International Centre for Diarrheal Disease and Research, Bangladesh. Then, all the animals were kept in ambient conditions with a 12:12 h dark-light cycle. Animals were permitted free access to drinking water and pellet diet ad libitum. Animals were acclimatized for 7 days in the laboratory environment earlier to the study. The protocol used in this study was approved by the institutional animal ethics committee, Department of Pharmacy, International Islamic University Chittagong, Bangladesh (Pharm - P\&D - 61 / 08'19 - 128).

\section{Acute toxicity test}

The acute oral toxicity test was investigated according to the OECD guidelines and the following described method [13,14]. Mice were divided into 7 groups (control and test), composed of 6 mice in each group $(n=6)$. MEXX was administered orally to the test groups at the dosage of $500-2000 \mathrm{mg} / \mathrm{kg}$, whereas the positive control received $1 \%$ Tween 80 in distilled water. A commercial pellet feed and freshwater adlibitum were subsequently given to the mice. Experimental mice were observed for probable changes in behavior, adverse reactions, and fatalities for the next 3 days and subsequently to the next 14 days commencement of the experiment. 


\section{In vivo anti-nociceptive activity}

\section{Acetic acid-induced writhing feedback}

The acetic acid-induced writhing test was investigated with the established method described by Koster [15]. For specific dosing, 24 mice were divided into 4 groups $(n=6)$ where Group-I and Group-II received $1 \%$ Tween -80 in distilled water and diclofenac sodium $(10 \mathrm{mg} / \mathrm{kg} \mathrm{b.w})$, respectively. Treatment groups such as Group III and IV were administered with MEXX at the doses of 200 and 400 $\mathrm{mg} / \mathrm{kg}$ (b.w, p.o), respectively. After $30 \mathrm{~min}$ of administration, $0.6 \%$ acetic acid $(10 \mathrm{~mL} / \mathrm{kg}$ b.w) was injected intraperitoneally into the mice of all 4 groups. Thereafter, the animals were observed for $5-30$ min and counted the number of writhing responses such as twisting of the mice trunk, contraction of the abdomen and limbs. The percentages of inhibition for anti-nociceptive activity were calculated by the following formula:

$\%$ inhibition $=100 \times[(\mathrm{C}-\mathrm{T}) / \mathrm{C}]$

where $\mathrm{C}$ is the mean number of writhing (control) and $\mathrm{T}$ is the mean number of writhing (test).

\section{Formalin-induced paw licking feedback}

The formalin test in experimental mice was carried out with slight modification of the established method [16]. In this investigation, all the mice were separated into 4 groups $(n=6)$ where Group I and Group II were treated with $1 \%$ Tween - 80 in distilled water and diclofenac sodium $(10 \mathrm{mg} / \mathrm{kg}, \mathrm{b} . \mathrm{w})$ which served as control and standard, respectively. Test groups (Group III and IV) received MEXX at the doses of 200 and $400 \mathrm{mg} / \mathrm{kg}$ (b.w, p.o), respectively. $30 \mathrm{~min}$ after the administration of all doses, $2.5 \%$ formalin solution $(\mathrm{v} / \mathrm{v}, 20 \mu \mathrm{L})$ was injected into the sub-plantar region of the right hind paw to induce nociception. Subsequently, pain response exhibited by experimental mice was measured by the observation of licking and biting of the injected paw which was recorded at $0-5$ min (neurogenic phase) and 15 - 30 min (inflammatory phase). The percentage of inhibition of licking time was calculated using the following ratio:

$\%$ inhibition $=100 \times[(\mathrm{C}-\mathrm{T}) / \mathrm{C}]$

where $\mathrm{C}$ is the mean of licking time (control) and $\mathrm{T}$ is the mean of licking time (test).

\section{In silico study}

\section{Identification of compound}

The structure of trans-5-hydroxypipecolic acid (PubChem CID: 177803) was downloaded from the PubChem database (www.pubchem.ncbi.nlm.nih.gov) and the evaluation of its pharmacological activity was conducted through molecular docking and pharmacokinetic analysis.

\section{Molecular docking study}

Ligand preparation

Downloaded structure of trans-5-hydroxypipecolic acid was prepared by using LigPrep wizard of Schrödinger maestro and generation of possible ionization state was directed using Epik at $\mathrm{pH} 7.0 \pm 2.0$ to calculate tautomer and understand the protonation state in biological condition [22]. Assigning the bond orders, minimization of each structure was executed by setting the OPLS_2005 force field.

\section{Protein preparation}

PDE4 (PDB ID:4WCU) [17], COX-1 (PDB ID: 2OYE) [7] and COX-2 (PDB ID:3HS5) [18] receptor were downloaded from the RCSB Protein Data Bank. Protein preparation wizard in Schrödinger Maestro was used for structure refinement of selected receptor proteins. The bond sequences were specified followed by the addition of hydrogens to overwhelming atoms. Also, the selenomethionines were transformed into methionines and water molecules were erased. Finally, after creating 0-order bonds 
to metals and disulfide bonds, minimization was performed utilizing the default constraint of RMSD 0.30 Å and force field OPLS_2005 [5].

\section{Active site selection}

The active sites on target receptors were selected by the PockDrug server which estimates pocket druggability using the ligand proximity method [19]. Setting proximity threshold to $5.5 \AA$, the pocket with the highest probability of druggability was selected [20].

\section{Receptor grid generation}

Selected protein grids were generated using Glide of Schrödinger maestro by maintaining the default variables of van der Waals scaling factor 1.00, partial charges cutoff 0.25 and an OPLS_2005 force field. A bounding box for individual receptors was created to such extent that it holds the entire active site residues.

\section{Docking simulation}

Standard precision ligand docking was performed in Glide of Schrodinger maestro where penalties were employed to non-cis/trans amide bonds. Van der Waals scaling factor and partial charges cutoff were set to 0.80 and 0.15 , respectively. Energy minimized posture was applied for final scoring and expressed as docking score. The poses and docking score value of selected compounds and standard drug with each selected receptor was recorded [21]. In addition, bond interaction was analyzed by using Biovia Discovery Studio Visualizer software.

\section{ADME analysis and toxicological properties prediction}

ADME analysis of trans-5-hydroxypipecolicacid was determined based on the Lipinski's rule by using the SwissADME online server, where toxicological properties were predicted using the admetSAR server (online tool) [22].

\section{Statistical analysis}

The results were presented as mean \pm S.E.M. (standard error of the mean). $P<0.05, P<0.01$ and $P<0.001$ were considered statistically significant compared with the control group followed by Dunnett's multiple comparison tests using 1-way ANOVA (GraphPad Prism 6.0).

\section{Results and discussion}

Qualitative and quantitateve phytochemical screening

Qualitative phytochemical screening determined the presence of carbohydrates, flavonoids, alkaloids, proteins and tannins (data not shown). Total phenolic and total flavonoid contents were calculated from the regression analysis and their results were presented in Table 1. Values are representing as mean \pm SEM $\quad(n=3)$. Plants containing flavonoids are responsible for a variety of pharmacological activities including anti-inflammatory and anti-nociceptive activity [23]. Also, the presence of alkaloids in plant extract blocks the metabolic pathway of arachidonic acid to prevent inflammation [24]. Quantitative phytochemical screening revealed that MEXX contains a high quantity of phenol and flavonoids, which might be responsible for anti-inflammatory and analgesic activity [25].

Table 1 Total phenolic and flavonoid contents of MEXX.

\begin{tabular}{ccc}
\hline Extract & $\begin{array}{c}\text { Phenolic content } \\
\text { (mg GAE/g dried extract) }\end{array}$ & $\begin{array}{c}\text { Flavonoid content } \\
\text { (mg QE/g dried extract) }\end{array}$ \\
\hline MEXX & $1222.66 \pm 0.66$ & $325.33 \pm 1.76$ \\
\hline
\end{tabular}

GAE: Gallic acid equivalent; QE: Quercetin equivalent. MEXX: methanolic extract of Xylia xylocarpa 


\section{In vitro anti-inflammatory activity}

Membrane stabilization activity

In the membrane stabilization activity of MEXX, the inhibition of hemolysis was observed to be dose conditional and significantly $(p<0.05)$ raised the protection of hemolysis induced by hypotonic solution compared with the standard. The percentage of hemolysis were $15.63 \pm 1.22,31.28 \pm 1.78,45.97$ $\pm 1.89,53.55 \pm 1.44,58.76 \pm 1.28$ and $64.92 \pm 1.17 \%$ for MEXX, while hydrocortisone showed $55.54 \pm$ $1.44,68.37 \pm 1.45,75.44 \pm 1.99,79.34 \pm 1.01,86.56 \pm 1.56$ and $95.88 \pm 2.01 \%$ at the doses of $31.5,62.5$, $125,250,500$ and $1000 \mu \mathrm{g} / \mathrm{mL}$, respectively (Figure 1).

Membrane stabilization and inhibition of protein denaturation methods were selected to evaluate the anti-inflammatory activity of MEXX. The extract depicted a significant membrane stabilization effect by inhibiting hypotonic medium which induced lysis of human red blood cell membrane. Inflammation can cause lysis of lysosomal membrane, the release of lysosomal enzymes, and causes several types of disorders. NSAIDs (Non-steroidal anti-inflammatory drugs) act either by inhibiting lysosomal enzyme discharge or by stabilizing the lysosomal membrane [26]. Human red blood cell membranes are analogs of the lysosomal membrane. Therefore, it can be assumed that MEXX indirectly inhibits the release of lysosomal components and stabilizing the lysosomal membrane which prevents tissue inflammation and damage [2]. Moreover, it was documented that protein denaturation is one of the reasons prompting rheumatoid arthritis which also might be the cause of the production of autoantigens in certain arthritic diseases. The mechanism of protein denaturation probably leads to the alteration of electrostatic, hydrophobic, hydrogen, and disulphide bonding [23]. The results revealed that MEXX significantly inhibited thermally-induced protein denaturation which might be the cause of anti-arthritic and antiinflammatory activity.

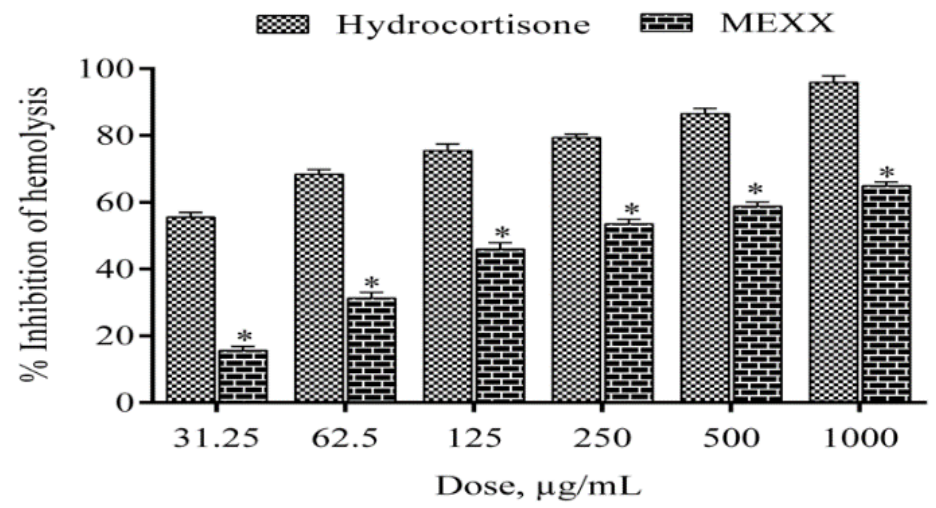

Figure 1 Percentage inhibition of hemolysis by MEXX and standard drug.

Results are expressed as mean $\pm \operatorname{SEM}(\mathrm{n}=3)$. The highest percentage inhibition for hemolysis and the standard hydrocortisone was $68.37 \pm 1.45$ and $95.88 \pm 2.01 \%$, respectively at $1000 \mu \mathrm{g} / \mathrm{mL}$. $* p<0.05$, significantly different from standard.

\section{Inhibition of protein denaturation}

In the protein denaturation test, the percentage of inhibition by MEXX and diclofenac sodium significantly $(p<0.05)$ increased dose-dependently. The highest inhibition by MEXX was calculated at $67.93 \pm 1.33 \%$ at $1000 \mu \mathrm{g} / \mathrm{mL}$, whereas diclofenac sodium (standard) showed $94.22 \pm 1.42 \%$ inhibition of protein denaturation at the same dose (Figure 2). 


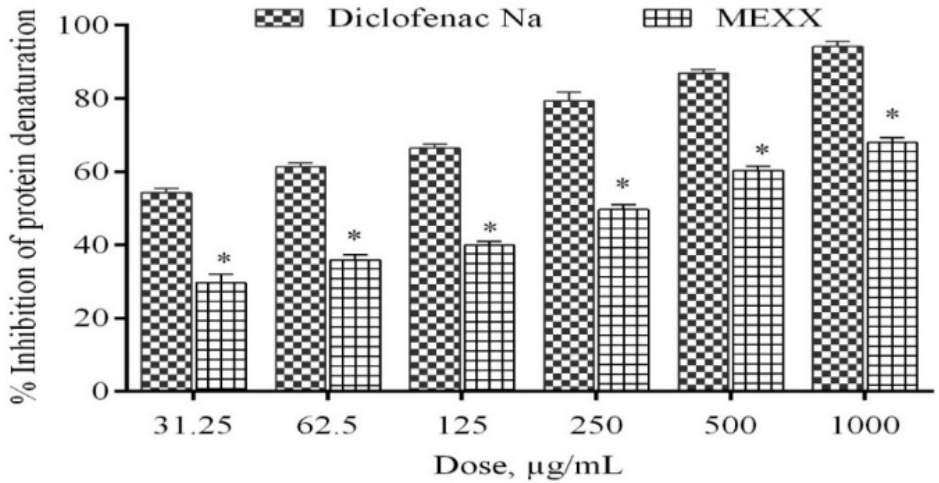

Figure 2 Percentage inhibition of protein denaturation by MEXX and standard drug. Values are expressed as mean $\pm \operatorname{SEM}(\mathrm{n}=3)$. ${ }^{*} p<0.05$, significantly different from standard.

\section{Acute toxicity study}

Toxicity evaluation of MEXX did not show any allergic reactions, toxicity, and mortality at 500, 1000 and $2000 \mathrm{mg} / \mathrm{kg}$ doses after the observation of $72 \mathrm{~h}$. These responses recommended that MEXX is non-toxic and safe at up to $2000 \mathrm{mg} / \mathrm{kg}$ dose in the mice model.

\section{In vivo anti-nociceptive activity}

\section{Acetic acid-induced writhing feedback}

In this test, MEXX exhibited 13.67 and $51.37 \%$ inhibition of writhing at the doses 200 and 400 $\mathrm{mg} / \mathrm{kg}$ body weight, respectively whereas diclofenac sodium showed $66.67 \%$ inhibition of writhing at the doses of $10 \mathrm{mg} / \mathrm{kg}$. These results were statistically significant when compared with the control (Table 2). Prior to in vivo investigations, this study also evaluated the preliminary acute toxicity test in the mice model which exhibited an extensive range of non-toxic and safety profiles of MEXX. Therefore, an acetic acid-induced writhing test has been performed for the investigation of peripheral anti-nociceptive activity [27]. Induction of acetic acid is responsible for the production of abdominal constriction as well as visceral inflammatory pain due to the release of endogenous substances [2]. In this study, acetic acidinduced pain sensation is triggered either by the liberation of visceral pro-inflammatory mediators such asserotonin, bradykinin, histamine, prostaglandins(PGs), cyclooxygenase (COX), cytokines (IL-8, TNF- $\alpha$ and IL-1 $\beta$ ), and lipoxygenase (LOX) or by the activation of chemo-sensitive nociceptors which excite peripheral nociceptive neurons [4]. As per the responses of experimental mice, MEXX significantly inhibited acetic acid-induced writhing which suggested that the extract has analgesic components which are inhibiting the release of nociceptive mediators or blocking the pain receptors. In addition, it is possible that the neurotransmitter system namely cholinergic, serotonergic, purinergic, catecholaminergic, opioid, cannabinoid, GABAergic systems along with ATP-gated potassium channels might be involved in the anti-nociceptive mechanism [2].

Table 2 Anti-nociceptive effect of MEXX in acetic acid-induced abdominal writhing test in mice.

\begin{tabular}{clc}
\hline Treatment & Writhing & \% of inhibition \\
\hline Control & $61.00 \pm 2.13$ & - \\
Diclofenac Na $(10 \mathrm{mg} / \mathrm{kg})$ & $20.33 \pm 1.46^{* * *}$ & 66.67 \\
MEXX $(200 \mathrm{mg} / \mathrm{kg})$ & $52.66 \pm 1.55^{* *}$ & 13.67 \\
MEXX $(400 \mathrm{mg} / \mathrm{kg})$ & $29.66 \pm 1.48^{* * *}$ & 51.37 \\
\hline
\end{tabular}

MEXX: Methanol extract of Xylia xylocarpa; Values are presented as mean \pm SEM $(\mathrm{n}=6) . * * p<0.01$ and $* * * p<0.001$ compared with the control group (Dunnett's test). 


\section{Formalin-induced paw licking feedback}

In the formalin-induced paw licking test, the effects of MEXX at 200 and $400 \mathrm{mg} / \mathrm{kg}$ doses are demonstrated in the Table 3. During early phase at $400 \mathrm{mg} / \mathrm{kg}$, paw licking duration was observed 31.60 $\pm 2.44 \mathrm{~s}$ with a pain inhibition percentage of $54.64 \%$ while during the latter phase at $400 \mathrm{mg} / \mathrm{kg}$ the inhibition was reported $25.22 \pm 2.43 \mathrm{~s}$ with pain inhibition of $43.82 \%$. Furthermore, MEXX $200 \mathrm{mg} / \mathrm{kg}$ in both early and late phase depicted 42.11 and $23.52 \%$ pain inhibition respectively whereas diclofenac sodium (standard) exhibited obvious pain inhibition by $75.13 \%$ in the early phase and $63.29 \%$ in the late phase. Since the acetic acid-induced writhing test does not distinguish between central or peripheral antinociceptive responses, we performed a formalin-induced paw licking test to evaluate neurogenic and inflammatory pain responses of MEXX [28]. This test showed biphasic nociceptive reactions such as an early phase (neurogenic phase) reaction and late phase (inflammatory phase) reaction [18]. Administration of formalin exhibited an acute nociceptive neurogenic pain due to direct triggers of nociceptive fibers (sensory $\mathrm{C}$ and A $\delta$ fibers) through the release of neuropeptides (substance P). On the other hand, an inflammatory pain response is slowed down by the release of chemical substances including serotonin, bradykinin, histamine and prostaglandins (PGs) [29]. The present study revealed that MEXX suppressed the pain response against both phases (neurogenic and inflammatory) of formalininduced pain which indicates the extract produced significant anti-nociceptive effects centrally and peripherally [2].

Table 3 Anti-nociceptive effect of MEXX in formalin-induced licking test in mice.

\begin{tabular}{ccccc}
\hline Treatment & Early phase(s) & $\begin{array}{c}\text { \% Inhibition of } \\
\text { early phase }\end{array}$ & Late phase(s) & $\begin{array}{c}\text { \% Inhibition } \\
\text { of late phase }\end{array}$ \\
\hline $\begin{array}{c}\text { Control } \\
\text { Diclofenac Na }\end{array}$ & $69.67 \pm 1.48$ & 0 & $44.89 \pm 1.75$ & - \\
$(10 \mathrm{mg} / \mathrm{kg})$ & $17.33 \pm 1.21 * * *$ & 75.13 & $16.48 \pm 1.49 * * *$ & 63.29 \\
MEXX $(200 \mathrm{mg} / \mathrm{kg})$ & $40.33 \pm 1.56 * * *$ & 42.11 & $34.33 \pm 2.58 * *$ & 23.52 \\
MEXX $(400 \mathrm{mg} / \mathrm{kg})$ & $31.60 \pm 2.44 * * *$ & 54.64 & $25.22 \pm 2.43 * * *$ & 43.82 \\
\hline
\end{tabular}

MEXX: Methanol extract of Xylia xylocarpa; values are presented as mean $\pm \operatorname{SEM}(n=6) . *^{*} p<0.01$ and $* * * p<0.001$ compared with the control group (Dunnett's test).

\section{In silico study}

\section{Molecular docking study for anti-inflammatory and anti-nociceptive activity}

In this study, trans-5-hydroxypipecolic acid exhibited $-6.539 \mathrm{kcal} / \mathrm{mol}$ docking score against PDE4 with $-38.608 \mathrm{kcal} / \mathrm{mol}$ glide energy whereas the standard (hydrocortisone) showed $-7.579 \mathrm{kcal} / \mathrm{mol}$ docking score with $-46.241 \mathrm{kcal} / \mathrm{mol}$ glide energy Table 4. In addition, docking for anti-nociceptive activity by trans-5-hydroxypipecolic acid provided $-5.214 \mathrm{kcal} / \mathrm{mol}$ and $-5.739 \mathrm{kcal} / \mathrm{mol}$ glide score against COX-1 and COX-2 enzyme, respectively. However, the standard (diclofenac sodium) did not show any docking interaction against COX-1 and COX-2 enzyme. The docking figures are exhibited in Figure 3. Their binding interactions between ligand and protein are presented in Table 5. Furthermore, molecular docking was performed to understand ligand-receptor interaction and correlate the results with our present experimental findings to unravel the molecular mechanisms. In computer-assisted drug design (CADD), molecular docking is a crucial technique to find out the potential lead compounds and use them in medicinal and pharmaceutical research [7]. Additionally, it is also used to evaluate the binding interaction of compounds against essential receptors with several types of bonds such as hydrogen and hydrophobic bond [5]. In this experiment, the identified compound trans-5-hydroxypipecolic acid from xylia xylocarpa leaves was subjected to standard precision (SP) docking against PDE4 (phosphodiesterase-4, PDB ID: 4WCU), COX-1 (cyclooxygenase-1, PDB ID: 2OYE) and COX-2 
(cyclooxygenase-2 PDB ID: 3HS5) enzymes (Table 4). Trans-5-hydroxypipecolic acid inhibited the PDE4 receptor through hydrogen bond with ASP-318 and hydrophobic bonds with MG-502, HIS-160 for anti-inflammatory activity (Figure 4a). In case of anti-nociceptive activity, trans-5-hydroxypipecolic acid suppressed COX-1 enzyme which exhibited hydrogen interaction to ILE-523 and hydrophobic interactions to GLY-526, TYR-385 (Figure 4b). On the other hand, ligand bound to COX-2 enzyme exhibited 3 hydrogen bonds with TYR-148, THR-212, ASN-382, and a hydrophobic bond with COH-619 (Figure 4c) for anti-nociceptive effect.

Table 4 Docking score of the trans-5- hydroxypipecolic acid.

\begin{tabular}{ccccc}
\hline Receptor & Ligand & $\begin{array}{c}\text { Docking } \\
\text { score } \\
\text { (kcal/mol) }\end{array}$ & $\begin{array}{c}\text { Glide model } \\
\text { (kcal/mol) }\end{array}$ & $\begin{array}{c}\text { Glide energy } \\
\text { (kcal/mol) }\end{array}$ \\
\hline $\begin{array}{c}\text { PDE4 } \\
\text { (pdb:4WCU) }\end{array}$ & Trans-5- hydroxypipecolic acid & -6.539 & -61.87 & -38.608 \\
\hline $\begin{array}{c}\text { COX-1 } \\
(\text { pdb:2OYE) }\end{array}$ & Trans-5- hydroxypipecolic acid & -5.214 & -31.444 & -46.241 \\
\hline $\begin{array}{c}\text { COX-2 } \\
(\mathrm{pdb}: 3 H S 5)\end{array}$ & Drans-5- hydroxypipecolic acid & -5.739 & -43.5811 & - \\
& Diclofenac Na (Standard) & - & - & -31.48 \\
\hline
\end{tabular}

Table 5 Binding interactions of trans-5-hydroxypipecolic acid.

\begin{tabular}{lcc}
\hline \multicolumn{1}{c}{ Proteins } & $\begin{array}{c}\text { Hydrogen bond interactions } \\
\text { Amino acid residue }\end{array}$ & $\begin{array}{c}\text { Hydrophobic interactions } \\
\text { Amino acid residue }\end{array}$ \\
\hline PDE4 (PDB ID :4WCU) & ASP-318 & MG-502, HIS-160 \\
COX-1 (PDB ID:2OYE) & ILE-523 & GLY-526, TYR-385 \\
COX-2 (PDB ID:3HS5) & TYR-148, THR-212, ASN-382 & COH-619 \\
\hline
\end{tabular}


(a)

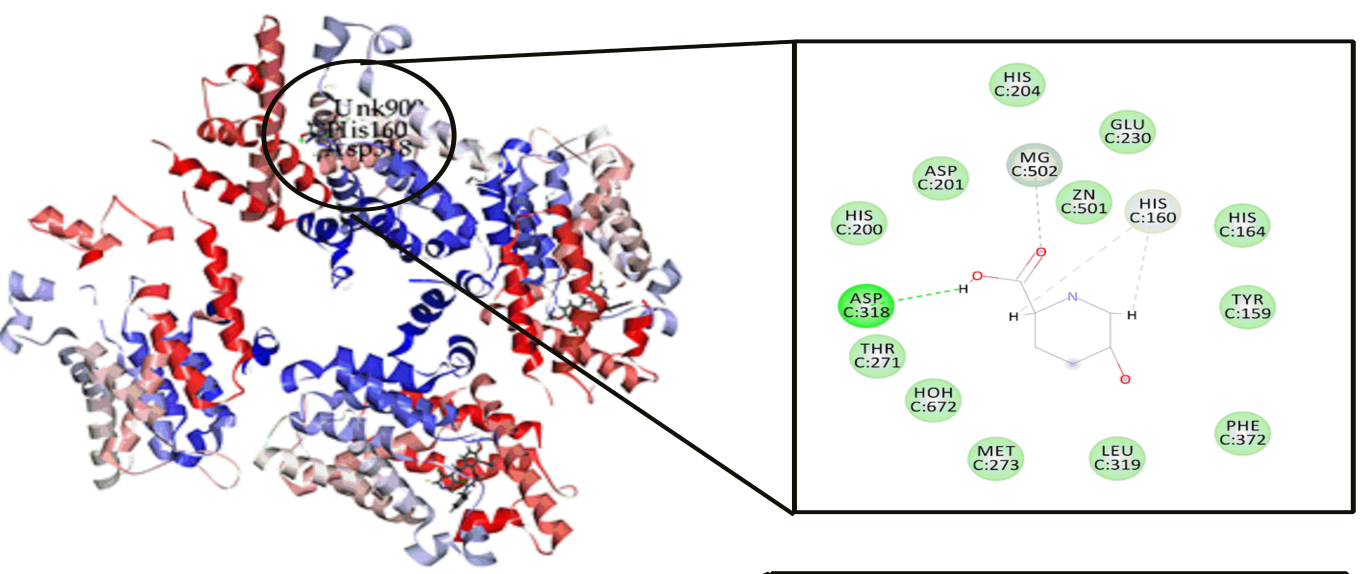

(b)

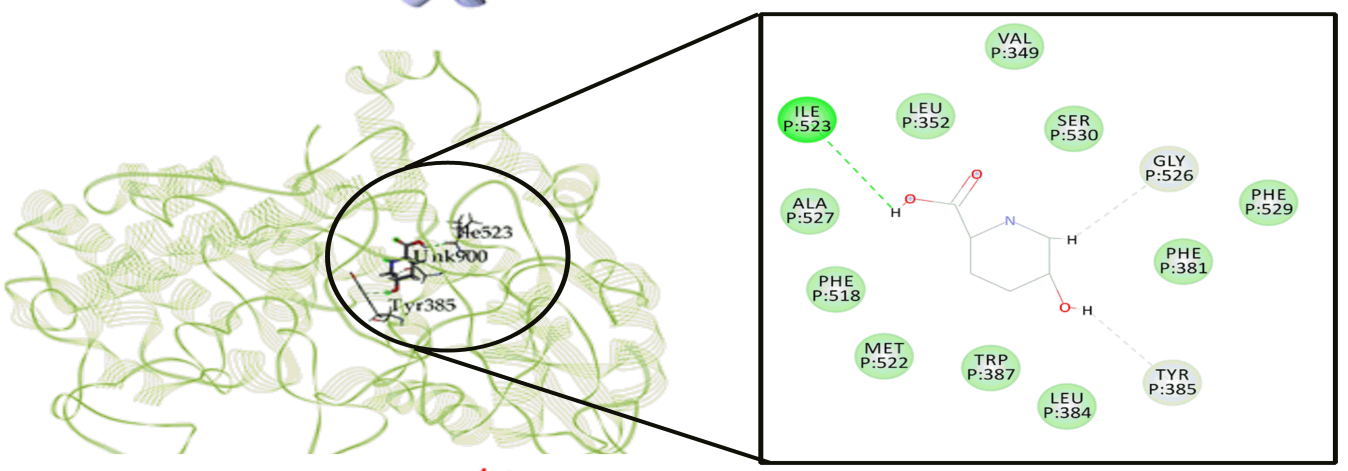

(c)

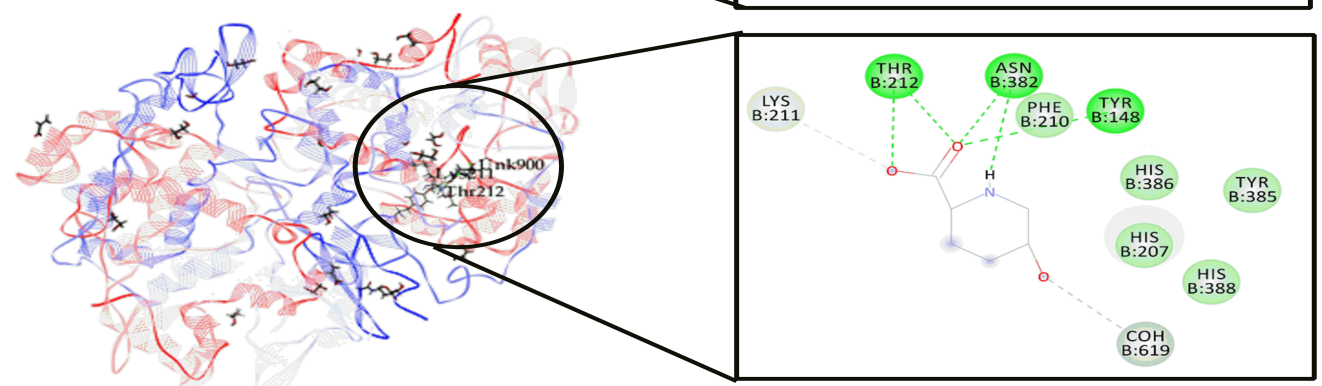

Figure 3 Visualization of the molecular docking interaction of trans-5-hydroxypipecolic acid with (a) PDE4 (pdb:4WCU), (b) COX-1 (pdb:2OYE), (c) COX-2 (pdb:3HS5).

\section{ADME analysis and Toxicological properties prediction}

The pharmacokinetic properties of trans-5-hydroxypipecolic acid were determined based on the Lipinski's rule and demonstrated in Table 6. According to the Lipinski's rule, trans-5-hydroxypipecolic acid exhibited no violations which indicated that the compound had acceptable pharmacokinetic properties and good oral bioavailability. Furthermore, toxicological properties of trans-5hydroxypipecolic acid revealed the compound to be non-Ames toxic, non-carcinogenic, and having weak rat acute toxicity properties (Table 7).

In addition, ADME analysis and toxicological properties predicted that the compound had good oral bioavailability and was suggested to be safe and non-toxic. 
Table 6 Pharmacokinetic properties of trans-5- hydroxypipecolic acid.

\begin{tabular}{ccc}
\hline Lipinski's rule & Trans-5-hydroxypipecolic acid & Lipinski’s violation \\
\hline Molecular weight $(<500)$ & $145.16 \mathrm{~g} / \mathrm{mol}$ & \\
Hydrogen bond acceptor $(<10)$ & 4 & 0 \\
Hydrogen bond donor $(\leq 5)$ & 3 & \\
High lipophilicity $(\log \mathrm{P} ; \leq 5)$ & 0.81 & \\
\hline
\end{tabular}

Table 7 Toxicological properties of trans-5- hydroxypipecolic acid.

\begin{tabular}{cc}
\hline Parameters & Trans-5-hydroxypipecolic acid \\
\hline Ames Toxicity & NAT \\
Carcinogens & NC \\
Acute oral toxicity & III \\
Rat acute toxicity & 1.9048 \\
\hline
\end{tabular}

NAT: Non-Ames toxic; NC: Non-carcinogenic; Category-III means (500 mg/kg > LD50 < 5000 mg/kg).

\section{Conclusions}

In conclusion, the findings of this experiment suggested that methanolic extract of Xylia xylocarpa leaves showed significant anti-inflammatory activity observed through membrane stabilization and inhibition of protein denaturation. In addition, MEXX exhibited remarkable central and peripheral antinociceptive activity against chemical-induced pain models. It can be predicted that phytoconstituents of MEXX such as flavonoids, phenols and alkaloids could be vital for anti-arthritic and analgesic effects by inhibiting the inflammatory mediators. Furthermore, ligand docking investigation speculated that identified compound trans-5-hydroxypipecolic acid inhibited phosphodiesterase-4 (PDE4) and cyclooxygenase (COX-1 and COX-2) with potential binding attraction as well as exhibited good pharmacokinetics profile as well as toxicological properties. However, further mechanistic investigations are required to identify active compounds of Xylia xylocarpa and their mechanism to validate these effects.

\section{Acknowledgement}

The authors thank the authority of International Islamic University Chittagong for their necessary and logistic support in the progress of the research. 


\section{References}

[1] JNR Moni, M Adnan, AM Tareq, MI Kabir, ASMA Reza, MS Nasrin, KH Chowdhury, SAJ Sayem, MA Rahman, AHMK Alam, SB Alam, MA Sakib, KK Oh, DH Cho and R Capasso. Therapeutic potentials of syzygium fruticosum fruit (seed) reflected into an array of pharmacological assays and prospective receptors-mediated pathways. Life 2021; 11,155.

[2] KH Hossain, MA Rahman, M Taher, J Tangpong, D Hajjar, W Alelwani, AA Makki and ASMA Reza. Hot methanol extract of Leea Macrophylla (Roxb.) manages chemical-induced inflammation in Rodent Model. J. King Saud Univ. Sci. 2020; 32, 2892-9.

[3] ASMA Reza, MS Hossain, S Akhter, MR Rahman, MS Nasrin, MJ Uddin, G Sadik and AHM K Alam. In vitro antioxidant and cholinesterase inhibitory activities of Elatostema papillosum leaves and correlation with their phytochemical profiles: A study relevant to the treatment of Alzheimer's disease. BMC Compl. Alternative Med. 2018; 18, 123.

[4] MS Hossain, ASMA Reza, MM Rahaman, MS Nasrin, MRU Rahat, MR Islam, MJ Uddin, MA Rahman. Evaluation of morning glory (Jacquemontia tamnifolia (L.) Griseb) leaves for antioxidant, antinociceptive, anticoagulant and cytotoxic activities. J. Basic Clin. Physiol Pharmacol. 2018; 29, 291-9.

[5] Adnan M, Chy M, Uddin N, Kamal A, Chowdhury KAA, Rahman M, Reza A, Moniruzzaman M, Rony SR and Nasrin M. Intervention in neuropsychiatric disorders by suppressing inflammatory and oxidative stress signal and exploration of In silico studies for potential lead compounds from Holigarna caustica (Dennst.) Oken leaves. Biomolecules 2020; 10, 561.

[6] P Ansari, MJ Uddin, MM Rahman, M Abdullah-Al-Mamun, MR Islam, MH Ali and ASMA Reza. Anti-inflammatory, anti-diarrheal, thrombolytic and cytotoxic activities of an ornamental medicinal plant: Persicaria orientalis. J. Basic Clin Physiol. Pharmacol. 2017; 28, 51-8.

[7] MJ Uddin, ASMA Reza, M Abdullah-Al-Mamun, MSH Kabir, MS Nasrin, S Akhter, MSI Arman and MA Rahman. Antinociceptive and Anxiolytic and sedative effects of methanol extract of Anisomeles indica: An experimental assessment in mice and computer aided models. Front. Pharmacol. 2018; 9, 246.

[8] P Siddhuraju, K Vijayakumari and K Janardhanan. Nutrient and chemical evaluation of raw seeds of Xylia xylocarpa: An underutilized food source. Food Chem. 1995; 53, 299-304.

[9] LMT Lam, MTT Nguyen, HX Nguyen, PH Dang, NT Nguyen, HM Tran, HT Nguyen, NM Nguyen, BS Min, JA Kim, JS Choi and MV Can. Anti-cholinesterases and memory improving effects of Vietnamese Xylia xylocarpa. Chem. Cent. J. 2016; 10, 48.

[10] PS Nakmee, S Khuntong and N Nuengchamnong. Phytochemical constituents with antimicrobial and antioxidant activities from Xylia xylocarpa (Roxb.) Taub. Sawdust Extracts. Chiang Mai J. Sci. 2016; 43, 11-21.

[11] L Mester, L Szabados, M Mester and N Yadav. Identification by 13C NMR spectroscopy of trans5-hydroxypipecolic acid in the leaves of Xylia xylocarpa, a new inhibitor of platelet agregation induced by serotonin. Planta Med. 1979; 35, 339-41.

[12] H Mobarak, MS Meah, N Sikder, M Tareq, A Azad, R Khatun, MS Nasrin, MO Raihan and AA Reza. Investigation of Preliminary phytochemicals, analgesic, anti-arthritic, thrombolytic and cytotoxic activities of Begonia roxburghii (Miq.) DC. Leaves. Med. One 2018; 2, e180001.

[13] MF Khan, FB Kader, M Arman, S Ahmed, C Lyzu, SA Sakib, SM Tanzil, AFMIU Zim, MAS Imran, T Venneri, B Romano, MA Haque and R Capasso. Pharmacological insights and prediction of lead bioactive isolates of Dita bark through experimental and computer-aided mechanism. Biomed. Pharmacother. 2020; 131, 110774.

[14] OECD iLibrary. Testing No. 423: Acute oral toxicity-OECD guideline for the testing of chemicals section 4. OECD Publishing, 2002.

[15] R Koster, M Anderson and EJD Beer. Acetic acid for analgesic screening. Fed. Proc. 1959; 18, 412-7. 
[16] M Gaertner, L Müller, JF Roos, G Cani, ARS Santos, R Niero, JB Calixto, RA Yunes, FD Monache and $\mathrm{V}$ Cechinel-Filho. Analgesic triterpenes from Sebastiania schottiana roots. Phytomedicine $1999 ; 6,41-4$.

[17] AM Tareq, S Farhad, M Hasan, SS Chowdhury, SAJ Sayem and S Hossain. Experimental analysis of selected isolated compounds of Borreria species against inflammation using computational chemistry. In: Proceedings of the Bangladesh Society for Biochemistry and Molecular Biology, Chittagong, Bangladesh. 2019.

[18] S Ahmad, MS Nasrin, ASMA Reza, N Chakrabarty, MA Hoque, S Islam, MSH Kabir, SM Tareq, AHMK Alam, MA Haque and MSI Arman. Curculigo recurvata W.T. Aiton exhibits antinociceptive and anti-diarrheal effects in Albino mice and an in silico model. Anim. Model. Exp. Med. 2020; 3, 169-81.

[19] Hussein HA, Borrel A, Geneix C, Petitjean M, Regad L and Camproux A-C. PockDrug-Server: a new web server for predicting pocket druggability on holo and apo proteins. Nucleic acids research. 2015; 43, W436-W42.

[20] A Borrel, L Regad, H Xhaard, M Petitjean and AC Camproux. PockDrug: A model for predicting pocket druggability that overcomes pocket estimation uncertainties. J. Chem. Inf. Model. 2015; 55, 882-95.

[21] RBJ Auniq, MNU Chy, M Adnan, A Roy, MA Islam, TN Khan, MZ Hasan, S Ahmed, MF Khan, N Islam, MI Khan, MA Hossain, MA Kabir, MTH Mukut and S Islam . Assessment of antinociceptive and anthelmintic activities of Vitex Peduncularis Wall. leaves and in silico molecular docking, ADME/T, and PASS prediction studies of its isolated compounds. J. Compl. Med. Res. $2019 ; 10,170-85$.

[22] CA Lipinski, F Lombardo, BW Dominy and PJ Feeney. Experimental and computational approaches to estimate solubility and permeability in drug discovery and development settings. $A d v$. Drug Deliv. Rev. 2001; 46, 3-26.

[23] MA Hossen, ASMA Reza, AMA Ahmed, MK Islam, I Jahan, R Hossain, MF Khan, MRA Maruf, MA Haque and MA Rahman. Pretreatment of Blumea lacera leaves ameliorate acute ulcer and oxidative stress in ethanol-induced Long-Evan rat: A combined experimental and chemicobiological interaction. Biomed. Pharmacother. 2021; 135, 111211.

[24] MN Islam, H Tasnim, L Arshad, MA Haque, SM Tareq, ATMM Kamal, MM Rahman, ASMA Reza, KAA Chowdhury and AM Tareq. Stem extract of Albizia richardiana exhibits potent antioxidant, cytotoxic, antimicrobial, anti-inflammatory and thrombolytic effects through in vitro approach. Clin. Phytosci. 2020; 6, 60.

[25] ZM Babar, I Jaswir, AM Tareq, ASMA Reza, WM Azizi, M Hafidz, F Ahfter, M Hasan, S Farhad, MMR Uddin, SJ Ichwan, QU Ahmed, M Taher and I Mawa. In vivo anxiolytic and in vitro antiinflammatory activities of water-soluble extract (WSE) of Nigella sativa (L.) seeds. Nat. Prod. Res. 2019; 3, 1-6.

[26] S Akter, M Shah, AM Tareq, MS Nasrin, MA Rahman, ZM Babar, MA Haque, MJ Royhan, MN Mamun, ASMA Reza and TB Emran. Pharmacological effect of methanolic and hydro-alcoholic extract of coconut endocarp. J. Adv. Biotechnol. Exp. Ther. 2020; 3, 171-81.

[27] S Trongsakul, A Panthong, D Kanjanapothi and T Taesotikul. The analgesic, antipyretic and antiinflammatory activity of Diospyros variegata Kruz. J. Ethnopharmacol. 2003; 85, 221-5.

[28] MR Islam, MN Uddin, ASMA Reza, MNU Rana and K Farhana. In vivo evaluation of analgesic activity of methanolic extract of Laportea interrupea (L.) leaves. J. Chem. Pharm. Res. 2014; 6, 552-6.

[29] SMF Bellah, MN Islam, MR Karim, MM Rahaman, MS Nasrin, MA Rahman, ASMA Reza. Evaluation of cytotoxic, analgesic, antidiarrheal and phytochemical properties of Hygrophila spinosa (T. Anders) whole plant. J. Basic Clin. Physiol. Pharmacol. 2017; 28, 185-90. 